\title{
Preparation of Alkyl Halide as Intermediate Compound in Synthesis Cationic Surfactant Alkyl Trimethyl Ammonium Chloride
}

\author{
Asdani Muatika Sari ${ }^{1 *}$, Ani Suryani ${ }^{1}$, Puspa Dewi Lotulung ${ }^{2}$, and Silvester Tursiloadi ${ }^{2}$ \\ ${ }^{1}$ Surfactant and Bioenergy Research Center, Bogor Agricultural University, Jl. Raya Pajajaran no.1, Bogor, Indonesia \\ ${ }^{2}$ Research Center for Chemistry - Indonesian Institute of Sciences, Kawasan PUSPITEK Serpong, Indonesia \\ *Corresponding author: muatikasari@gmail.com
}

\begin{tabular}{|c|c|}
\hline$A R T I C L E I N F O$ & Abstract \\
\hline $\begin{array}{l}\text { Article history: } \\
\text { Received date :17 April } 2017 \\
\text { Revised date : } 2 \text { June } 2017 \\
\text { Accepted date : } 8 \text { June } 2017 \\
\text { Available online at : } \\
\text { http://inajac.lipi.go.id }\end{array}$ & $\begin{array}{l}\text { Cationic surfactant alkyl trimethyl ammonium chloride was synthesized } \\
\text { by quartenerisation of tertiary amines. Materials used in quartenerization } \\
\text { are tertiary amine and alkyl halide. Alkyl halide is a hydrocarbon } \\
\text { derivative in which one or more hydrogen is replaced with halogen. In } \\
\text { this research, thionyl chloride is used as a reactant. Thionyl chloride } \\
\left(\mathrm{SOCl}_{2}\right) \text { is often used because it is easier to make, the yield is greater and } \\
\text { byproducts are volatile. Alkyl halide is synthesized from the reaction of } \\
\text { hexadecvl alcohol with thionvl chloride }\left(\mathrm{SOCl}_{2}\right) \text { at a temperature of } 80^{\circ}\end{array}$ \\
\hline $\begin{array}{l}\text { Keywords: } \\
\text { Alkyl halide, reflux, thionyl chloride }\end{array}$ & $\begin{array}{l}\mathrm{C} \text { for } 24 \text { hours in a reflux reactor. This study managed to get hexadecyl } \\
\text { chloride from the reaction hexadecyl alcohol and thionyl chloride. It can } \\
\text { be seen from the results of FTIR, LC/MS and GC/MS. } \\
\text { (c) } 2017 \text { Indonesian Journal of Applied Chemistry. This is an open access } \\
\text { article under the CC BY-NC-SA license. }\end{array}$ \\
\hline
\end{tabular}

\section{INTRODUCTION}

Surfactant is a material used to reduce the surface tension. This material is typically used as a foaming agent for home care and personal care industry, defoaming agent in the chemical industry, and as an adjuvant material in the pesticide industry. One type of surfactant is a cationic surfactant or surfactants that have a positive ion, for example from the class of alkyl amines, fatty amines or ethoxy amines. One of the examples for cationic surfactants are alkyl trimethyl ammonium chloride commonly used in industry as an adjuvant material in pesticide formulations [4][5][7][8]. The adjuvant material used to improve the properties of pesticides, for example, to improve the retention of pesticides in the soil, and increase adsorption of pesticides in plants [7][8]. The addition of surfactant on pesticides also can reduce the risk of contamination from pesticides to the environment [1][11]. Cationic surfactants have also been used to change the nature of the pesticide by increasing the absorption of hydrophobic organic compounds (HOCS) to soil particles [1][2][3][9]11].
Cationic surfactant alkyl trimethyl ammonium chloride was synthesized by quartenerization of tertiary amines. Materials used in quartenerization is a tertiary amine and alkyl halide. Alkyl halide is a hydrocarbon derivative in which one or more hydrogen is replaced with halogen. Chemists often use the $\mathrm{RX}$ as a general notation for organic halides, $\mathrm{R}$ indicates alkyl and $\mathrm{X}$ for halogen groups. Most of alkyl halide is liquid and insoluble in water, but can be dissolved by liquid hydrocarbon. Alkyl halide most commonly encountered as an intermediate compound in the synthesis. They are easily converted into various types of other compounds and can be obtained through many ways, including the reaction between fatty alcohol with $\mathrm{HCl}, \mathrm{PCl}_{3}$ or $\mathrm{SOCl}_{2}$. The reaction are as follows:

$\begin{array}{llll}\mathrm{ROH}+\mathrm{HCl} & \rightarrow & \mathrm{RCl}+\mathrm{H}_{2} \mathrm{O} \\ \mathrm{ROH}+ & \mathrm{PCl} 3 & \rightarrow & \mathrm{RCl}+\mathrm{H}_{3} \mathrm{PO}_{4} \\ \mathrm{ROH}+\mathrm{SOCl}_{2} \rightarrow & \mathrm{RCl}+\mathrm{HCl}+\mathrm{SO}_{2}\end{array}$

In this research, thionyl chloride is used as a reactant . Thionyl chloride $\left(\mathrm{SOCl}_{2}\right)$ is often used because it is easier to make, the yield is 
greater and the byproducts are volatile $\left(\mathrm{SO}_{2}\right.$ and $\mathrm{HCl})$ [10], and the rest of the reagent is also easily removed. Thionyl chloride is a clear slightly yellowish solution. It evaporates in the air, boiling point $78.8^{\circ} \mathrm{C}$, at a temperature of $150^{\circ} \mathrm{C}$. It undergoes decomposition into sulfur chloride, sulfur dioxide and chlorine [10]. The purpose of this research is to get an alkyl halide from the reaction between fatty alcohol and thionyl chloride.

\section{EXPERIMENTAL SECTION}

\subsection{Materials}

Materials used are hexadecyl alcohol 70\% (PT Sinarmas). Thionyl chloride 99.6\% (PT Dipa) and pyridine $99.5 \%$ (Merck, Germany).

\subsection{Methods}

\subsubsection{Synthesis of alkyl halide}

The purpose of the synthesis of alkyl halides was to get an alkyl halide as an intermediate in the synthesis of cationic surfactants. The synthesis was conducted by reacting hexadecyl alcohol with thionyl chloride $\left(\mathrm{SOCl}_{2}\right)$ at a temperature of $80^{\circ} \mathrm{C}$ for 24 hours in a reflux reactor. The unwanted side products was eliminated by evaporation.

\subsubsection{Alkyl halide characterization}

The characterization aims to determine the functional groups, molecular weight and molecular structure. Functional groups were characterized using FTIR (Fourier Transformation Infra Red) IR-21 Shimadzu Prestige. Molecular weights were characterized using LC/MS (Liquid Chromatograph Mass Spectrometry) Mariner Biospectrometry Hitachi L 6200. Molecular structure was characterized using GC/MS (Gas Chromatograph Mass Spectrometry) Agilent 5977A.

\section{RESULT AND DISCUSSION}

\subsection{Synthesis of alkyl halide}

Synthesis of alkyl halides used hexadecyl alcohol and thionyl chloride $\left(\mathrm{SOCl}_{2}\right)$, so that the resulting product is hexadecyl chloride. The reactions that occured in the synthesis of alkyl halides and the cationic surfactant was a nucleophilic substitution reaction. Substitution reaction is a reaction in which an atom or ion or group is substituted to replace the atoms or ions or other groups. Nucleophile or nucleophilic is an electron or a pair of electrons that are attracted to a positive center, for example in the form of anion $\mathrm{OH}-$ or $\mathrm{CH} 3 \mathrm{O}-$, or molecules that can donate one pair to form a chemical bond. So that the nucleophilic substitution reaction is a reaction to the replacement of another atom or group with a compound by nucleophilic. The reaction mechanism is shown in Figure 1.
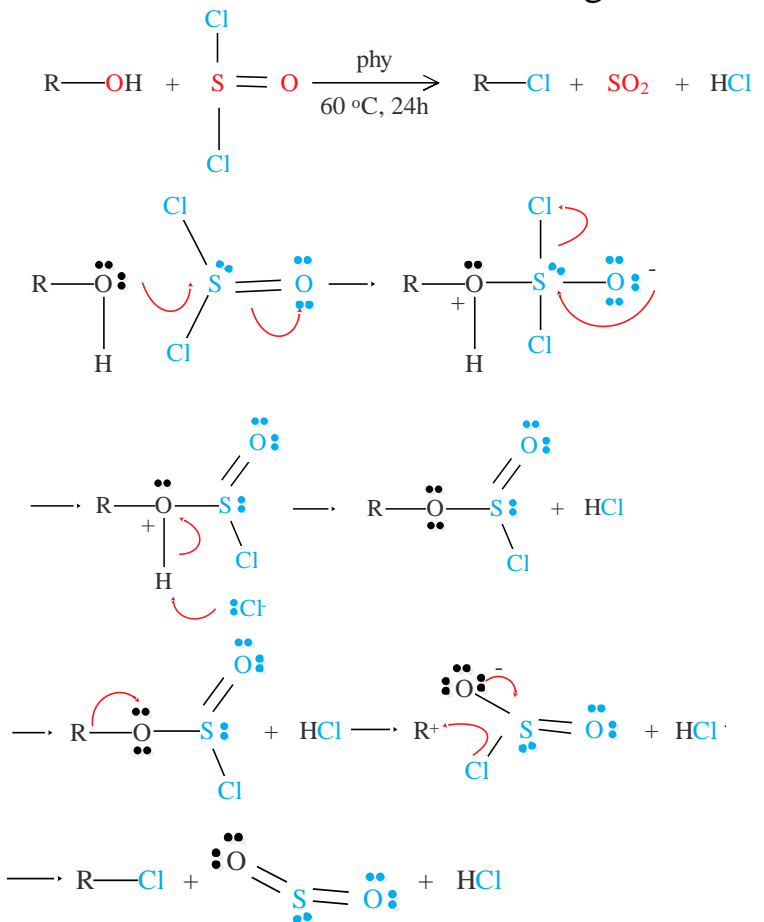

Fig 1. The mechanism of reaction formation of alkyl halides [10]

Oxygen in alcohol has a free electron pair and is nucleophilic which attack the sulfur in thionyl chloride. The double bond between the sulfur and oxygen break up, causing a bond between alcohol and thionyl chloride. This bond is called tetrahedral sulfur atom or ion oxonium. In this phase, the elimination of $\mathrm{Cl}(\mathrm{Cl})$ occured, which then bind hydrogen $(\mathrm{H})$ to form hydrochloric acid $(\mathrm{HCl})$. When the elimination of $\mathrm{Cl}$ took place, chlorosulfit deprotonization formed compounds. The $\mathrm{C}=\mathrm{O}$ group at chlorosulfit is very reactive to nucleophilic attack, in these conditions $\mathrm{Cl}$ has nucleophilic properties and attack the group $\mathrm{C}=\mathrm{O}$ at chlorosulfit. Finally it formed alkyl halides, sulfur oxides and hydrochloric acid. 


\subsection{Characteristic of FTIR (Fourier Transformation Infra Red)}

The formed compound is hexadecyl chloride. $\mathrm{C}_{16} \mathrm{H}_{33} \mathrm{Cl}$ is the molecular formula of hexadecyl chloride, where in the compound there are $\mathrm{C}-\mathrm{H}$ groups and $\mathrm{C}-\mathrm{Cl}$ groups. $\mathrm{C}-\mathrm{H}$ group spread in $2500-3000 \mathrm{~cm}^{-1}$ wave number and $\mathrm{C}-\mathrm{H}$ group spread in $600-800 \mathrm{~cm}^{-1}$ wave number. The FTIR spectrum alkyl halide shows the corresponding results where $\mathrm{C}-\mathrm{H}$ group spread in $2922.16 \mathrm{~cm}^{-1}$ wave number and $\mathrm{C}-\mathrm{Cl}$ group in $783.10 \mathrm{~cm}^{-1}$ wave number.

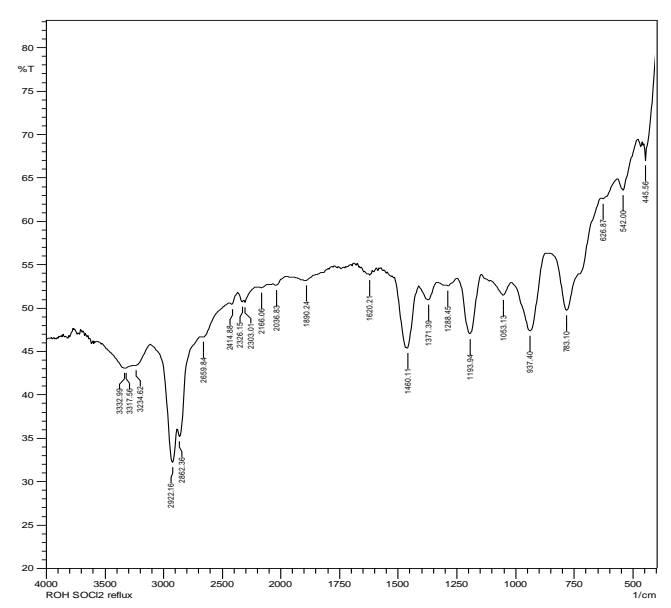

Fig 2. The FTIR spectrum hexadecyl chloride

\subsection{Characteristic of LC/MS (Liquid Chromatograph Mass Spectrometry)}

The results of LC/MS analysis can be seen in Figures 3 and 4 . The resulting product is hexadecyl chloride with $\mathrm{C}_{16} \mathrm{H}_{33} \mathrm{Cl}$ molecular formula and molecular weight of $260.94 \mathrm{~g} / \mathrm{mol}$. Based on the spectrum image, it can be seen that the alkyl halide has been formed. The characterization of LC/MS showed a molecular weight of hexadecyl chloride which is 261.63 $\mathrm{m} / \mathrm{z}$. This calculation is based on pseudomolecular ion, wherein the molecular weight of $260.94 \mathrm{~g} / \mathrm{mol}$ would read $261.63 \mathrm{~m} / \mathrm{z}$ $(\mathrm{M}+1)$ due to the addition of $\mathrm{H}+$ ions. Figure 3 showed 3 peaks, its means that the product contain at least 3 molecules. Rate time or retention time is the time which needed sample from first coloum until detector. So, from the retention time happened separating of molecule. According Figure 3 showed the peak of T2.2 is hexadecyl choliride.

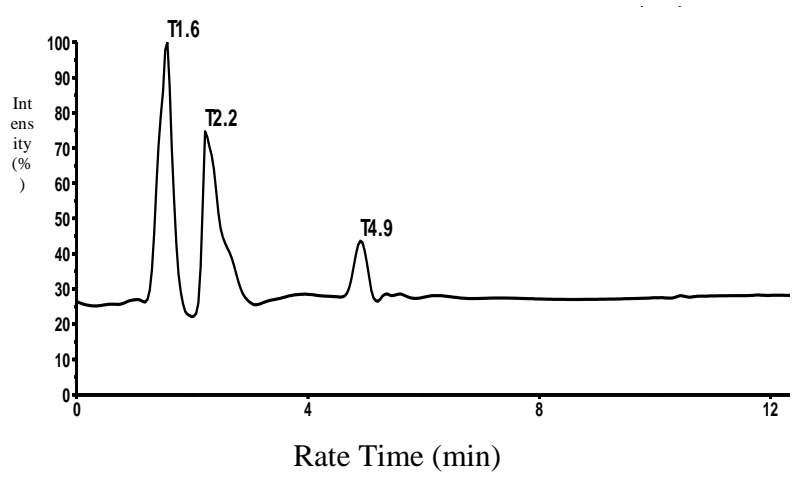

Fig 3. Chromatogram of hexadecyl chloride

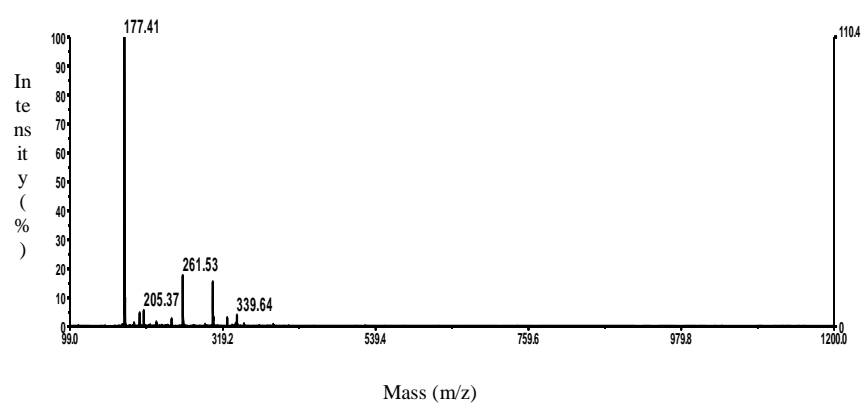

Fig 4. The mass spectrum of hexadecyl chloride

\subsection{Characteristic of GC/MS (Gas Chromatograph Mass Spectrometry)}

The characterization results of GC/MS can be seen in Figure 5. The spectrum of GC / MS showed a peak ion. The peak showed the compound contained in the product. Based on the peak of 19.0007 tool library is hexadecyl chloride.

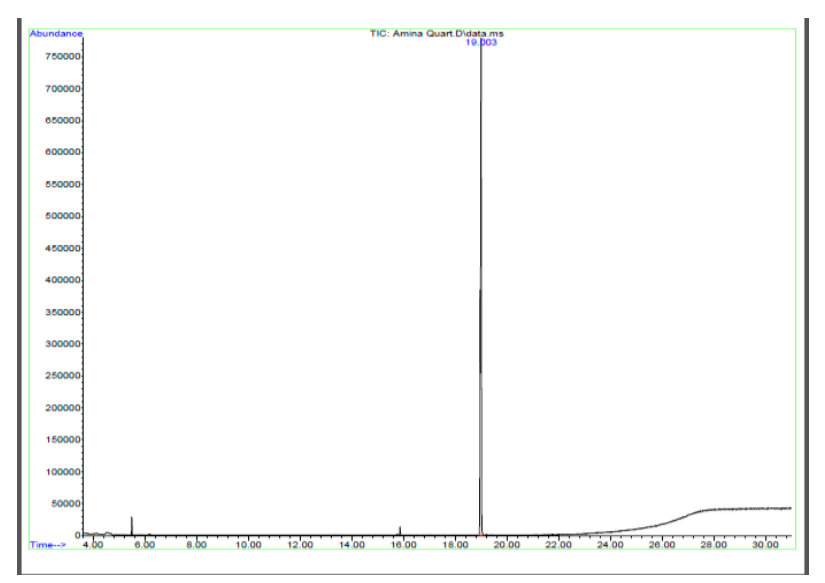

Fig 5. Spectrum GC/MS of hexadecyl triethyl ammonium chloride 


\section{CONCLUSION}

\subsection{Conclusion}

This study managed to get hexadecyl chloride from the reaction of hexadecyl alcohol and thionyl chloride which can be seen from the results of FTIR. C-H group spread in 2500$3000 \mathrm{~cm}^{-1}$ wave number and $\mathrm{C}-\mathrm{H}$ group spread in $600-800 \mathrm{~cm}^{-1}$ wave number. The molecular weight of $260.94 \mathrm{~g} / \mathrm{mol}$. The peak spectrum of GC/MS showed 19.0007.

\subsection{Suggestion}

Needs to be optimized in the synthesis of hexadecyl chloride in order to obtain a more optimal result.

\section{REFERENCES}

[1] Abu-ZreigM, Rudra RP, Dickinson WT. 2000. Influence of surfactants on leaching of atrazine through soil columns. Toxicol. Environ. Chem. 75:1-16.

[2] Brown MJ, Burris DR. 1996. Enhanced organic contaminant sorption on soil treated with cationic surfactants. Ground Water 34:734-744.

[3] Gao B, Wang X, Zhao J, Sheng G. 2001. Sorption and cosorption of organic contaminant on surfactant-modified soils. Chemosphere 43:1095-1102.

[4] Jimenez EI, Sanchez-Martin MJ, Sanchez-Camazano M. 1996. Pesricide adsorption in a soil water system in the presence of surfactant. Chemosphere Vol 32, No 9.

[5] Kazakevich Y, LoBrutto R. 2007. HPLC for Pharmaceutical Scientist. Canada (USA): John Wiley \& Sons Inc.

[6] Ostgard DJ, Olindo R, Berweiler M, Roder S, Tacke T. 2007. The cemoselective hydrogenation of tallow nitriles to unsaturated 10 fatty amines with carbon modified $\mathrm{Ni}$ catalyst. Catalysis Today 121:106-114.

[7] Rodriguez-Cruz MS, Sanchez-Martin MJ, Sanchez-Camazano M, Andrades MS. 2007. Modification of clay barriers with a cationic surfactant to improve the retention of pesticide in soil. Journal of Hazardous Materials B139 363-372.

[8] Rodriguez-Cruz MS, Sanchez-Martin MJ, Sanchez-Camazano M, Andrades MS.. 2007. Retention of pesticide in soil columns modified in situ and ex situ with a cationic surfactant. Science of the Total Environment 378:104-108.

[9] Sanchez L, Sanchez Rasero F, Dios G, Romero E, Pena, A. 2003. Enhanced soil sorption of methidathion using sewage sludge and surfactants. Pest. Manage. Sci. 59:857-864.

[10] Sudarmiko N. 1995. Sintesis, isolasi, dan karakterisasi sifat aktif permukaan ester sukrosa laurat. Skripsi. Bogor (ID): Fakultas Matematika dan Ilmu Pengetahuan Alam, Institut Pertanian Bogor.

[11] Wagner J, Chen H, Brownawell BJ, Westall JC. 1994. Use of cationic surfactants to modify soil surfaces to promote sorption and retard migration of hydrophobic organic compounds. Environ. Sci. Technol. 28:231-237. 